\title{
RESEARCH
}

Open Access

\section{Fat extract improves fat graft survival via proangiogenic, anti-apoptotic and pro- proliferative activities}

Hongjie Zheng ${ }^{\dagger}$, Ziyou Yu ${ }^{\dagger}$, Mingwu Deng ${ }^{\dagger}$, Yizuo Cai, Xiangsheng Wang, Yuda Xu, Lu Zhang ${ }^{*}$, Wenjie Zhang ${ }^{*}$ and Wei Li

\begin{abstract}
Background: Our previous study proved that nanofat could enhance fat graft survival by promoting neovascularization. Fat extract (FE), a cell-free component derived from nanofat, also possesses proangiogenic activity.
\end{abstract}

Objectives: The aim of this study was to investigate whether FE could improve fat graft survival and whether FE and nanofat could work synergistically to promote fat graft survival. The underlying mechanism was also investigated.

Methods: In the first animal study, human macrofat from lipoaspirate was co-transplanted into nude mice with FE or nanofat. The grafts were evaluated at 2, 4 and 12 weeks post-transplantation. In the second animal study, nude mice were transplanted with a mixture of macrofat and nanofat, followed by intra-graft injection of FE at days 1, 7, 14, 21 and 28 post-transplantation. The grafts were evaluated at 12 weeks post-transplantation. To detect the mechanism by which FE impacts graft survival, the proangiogenic, anti-apoptotic and pro-proliferative activities of FE were analysed in grafts in vivo and in cultured human vascular endothelial cells (HUVECs), adipose-derived stem cells (ADSCs) and fat tissue in vitro.

Results: In the first animal study, the weights of the fat grafts in the nanofat- and FE-treated groups were significantly higher than those of the fat grafts in the control group. In addition, higher fat integrity, more viable adipocytes, more CD31-positive blood vessels, fewer apoptotic cells and more Ki67-positive proliferating cells were observed in the nanofat- and FE-treated groups. In the second animal study, the weights of the fat grafts in the nanofat+FE group were significantly higher than those of the fat grafts in the control group. In vitro, FE showed proangiogenic effects on HUVECs, anti-apoptotic effects on fat tissue cultured under hypoxic conditions and an ability to promote ADSC proliferation and maintain their multiple differentiation capacity.

Conclusions: FE could improve fat graft survival via proangiogenic, anti-apoptotic and pro-proliferative effects on ADSCs. FE plus nanofat-assisted fat grafting is a new strategy that could potentially be used in clinical applications.

Keywords: Fat extract, Nanofat, Fat transplantation, Proangiogenic, Anti-apoptotic, Pro-proliferative

\footnotetext{
*Correspondence: luzhangmd@163.com; wenjieboshi@aliyun.com;

liweiboshi@163.com

${ }^{\dagger}$ Hongjie Zheng, Ziyou Yu and Mingwu Deng contributed equally to this

work.

Department of Plastic and Reconstructive Surgery, Shanghai Key Laboratory

of Tissue Engineering, Shanghai 9th People's Hospital, Shanghai Jiao Tong

University, 639 Zhi Zao Ju Road, Shanghai 200011, China
}

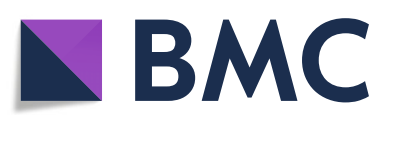

(c) The Author(s). 2019 Open Access This article is distributed under the terms of the Creative Commons Attribution 4.0 International License (http://creativecommons.org/licenses/by/4.0/), which permits unrestricted use, distribution, and reproduction in any medium, provided you give appropriate credit to the original author(s) and the source, provide a link to the Creative Commons license, and indicate if changes were made. The Creative Commons Public Domain Dedication waiver (http://creativecommons.org/publicdomain/zero/1.0/) applies to the data made available in this article, unless otherwise stated. 


\section{Background}

Soft tissue defects caused by congenital defects, trauma, tumour resection and ageing are the most common problems in plastic and reconstructive surgery. Traditional repairs include filling with artificial fillers and autologous tissue transplantation. The potential rejection reactions induced by artificial fillers limit their clinical application. With biocompatibility and a wide range of sources, autologous fat grafting has become one of the most commonly used methods for the treatment of soft tissue defects. However, the highly unpredictable absorption rate of grafted fats after fat transplantation reduces the efficacy of this method. The retention rate of grafted fats is reported to range from 20 to $80 \%$ [1-4].

To address this issue, numerous attempts have been made to increase fat graft survival. In the early stage after fat grafting, adipocytes obtain nutrients and oxygen through plasmatic diffusion from the surrounding tissues, and this process is limited to the peripheral zone of the grafted fat. In Hitomi Eto's research, only peripheral adipocytes survived, and the depth of the viable zone was approximately $300 \mu \mathrm{m}$ from the graft edge; almost all adipocytes located deeper than $300 \mu \mathrm{m}$ died within a few days after grafting [5]. Therefore, early revascularization of the grafted fat is crucial for survival, especially in patients who undergo large-volume fat grafting [5-10]. Co-transplantation of fat with proangiogenic growth factors (vascular endothelial growth factor (VEGF), platelet-derived growth factor (PDGF), basic fibroblast growth factor (bFGF), etc.) has been proven to enhance the fat graft retention rate by increasing revascularization. In 2006, Matsumoto et al. demonstrated that the stromal vascular fraction (SVF) isolated from fat tissues could improve the survival of fat grafts, and a cell-assisted lipotransfer strategy has been developed [11]. In recent years, adipose-derived stem cells (ADSCs) have been shown to improve survival by paracrine secretion of many kinds of growth factors and direct differentiation into adipocytes and endothelial cells [12-15]. However, enzymatic digestion during SVF isolation or ADSC culture raises safety concerns.

In 2013, Tonnard et al. first described the concept of nanofat, a liquid suspension derived from fat tissue that is obtained by mechanical emulsification and filtering, and showed remarkable improvements in skin quality [16]. Subsequent studies revealed that nanofat also has promising effects on skin rejuvenation, scar management and reconstruction of tissue defects [17-19]. Nanofat contains cellular and non-cellular components. It is processed simply by mechanical means without any chemicals or enzymes [16]. Therefore, nanofat is much safer and more time saving for clinical applications than SVF and ADSCs. In a previous study, we found that compared to the control group, co-transplantation of fat with nanofat yielded a higher graft retention rate, better histological structure and higher capillary density of grafts [20]. Subsequent assays have demonstrated that nanofat contains a large number of cytokines and growth factors (VEGF, transforming growth factor beta (TGF- $\beta$ ), bFGF, hepatocyte growth factor (HGF), granulocyte-macrophage colony-stimulating factor (GM-CSF), insulin-like growth factor 1 (IGF-1) and PDGF), which may account for the improvement of fat graft survival [20].

Fat extract (FE), the liquid fraction that is derived from nanofat using a mechanical approach to remove the cellular components and the lipid remnants, was first described in our previous study and showed proangiogenic effects in a murine model of limb ischaemia [21]. FE is a cell-free fraction that could avoid potential cellrelated concerns in clinical applications, such as genetic mutations, and the difficulties of long-term storage. In the present study, we aimed to evaluate the effects of FE on fat transplantation, to investigate the underlying mechanisms and to establish a new FE-assisted fat graft strategy for future clinical application.

\section{Methods}

\section{Nanofat and FE preparation}

After informed consent was obtained, lipoaspirate was obtained from the abdomen or thighs of five donors via standard vacuum-assisted liposuction from December 2017 to November 2018. All donors were healthy females with no underlying disease or diabetes mellitus. The mean body mass index was 24.86 , and the mean age was 28 years (range $21-40$ years). The study was approved by the Ethics Committee of Shanghai Jiaotong University School of Medicine, Shanghai, China. Macrofat was harvested via a standard 3-mm liposuction cannula with large side holes $2 \times 7 \mathrm{~mm}$ [16]. The lipoaspirate was allowed to settle for $15 \mathrm{~min}$ to allow the layers to separate by gravity sedimentation, and the superior oil and inferior blood layers were then removed by vacuum aspiration. The remaining fat layer was subsequently rinsed with saline 3 times in closed syringes and then centrifuged at $1200 \mathrm{rpm}$ for $4 \mathrm{~min}$ at $4{ }^{\circ} \mathrm{C}$. Any oil and fluid were removed again, and the remaining fat was collected for further processing.

Nanofat was obtained using Tonnard's technique [16]. Briefly, the nanofat was obtained by mechanical emulsification; the macrofat was transferred between two 10-cc syringes connected by a female-to-female Luer-Lok connector 60 times (B. Braun Medical Inc., Melsungen, Germany). FE was produced from nanofat by centrifugation, as previously described [21]. Briefly, the nanofat was centrifuged at $1200 \mathrm{rpm}$ for $5 \mathrm{~min}$, and the fat was separated into four layers. The third aqueous layer, namely, FE, was collected and filtered through a 0.22 $\mu \mathrm{m}$ filter (Corning Glass Works, Corning, NY, USA) for further use. 


\section{Mouse fat graft model}

All experiments were approved by the Animal Care and Experiment Committee of Shanghai Jiaotong University School of Medicine. Six-week-old male BALB/c-nu nude mice (Animal Laboratory, The Ninth People's Hospital, Shanghai Jiaotong University School of Medicine, Shanghai, China) were used in this study.

To determine the effects and investigate the mechanisms of FE on fat transplantation, four groups were included in the first experiment (Fig. 1a): the phosphate-buffered saline (PBS) group, the $\mathrm{FE}^{\mathrm{Low}}$ group, the $\mathrm{FE}^{\mathrm{High}}$ group and the nanofat group. In the PBS group, a mixture of $500 \mu \mathrm{l}$ of fat with $50 \mu \mathrm{l}$ of PBS was injected. In the nanofat group, a mixture of $500 \mu \mathrm{l}$ of fat with $50 \mu \mathrm{l}$ of nanofat was injected. In the $\mathrm{FE}^{\mathrm{Low}}$ group, $500 \mu \mathrm{l}$ of fat was injected with $7.5 \mu \mathrm{l}$ of $\mathrm{FE}$ and $42.5 \mu \mathrm{l}$ of $\mathrm{PBS}$, and the $\mathrm{FE}^{\mathrm{High}}$ group received $500 \mu \mathrm{l}$ of fat injected together with $37.5 \mu \mathrm{l}$ of FE and $12.5 \mu \mathrm{l}$ of PBS. The total volume of each graft was $550 \mu \mathrm{l}$. The average output ratio from nanofat to $\mathrm{FE}$ is $15 \%$; we added $7.5 \mu \mathrm{l}$ of $\mathrm{FE}$ in the $\mathrm{FE}^{\mathrm{Low}}$ group which was equivalent to $50 \mu \mathrm{l}$ of nanofat in the nanofat group. The amount of FE in the $\mathrm{FE}^{\mathrm{High}}$ group was 5 times that of the $\mathrm{FE}^{\mathrm{Low}}$ group. Thirty-six mice were used in this experiment, and the injection was performed in the dorsal region of nude mice (each mouse was injected at two sites) via 14-G needles, as indicated in Fig. 1a. Mice were sacrificed at 2, 4 and 12 weeks post-transplantation, and the fat grafts were harvested and weighed $(n=6)$.

To determine whether the nanofat and FE could work synergistically to promote fat graft survival, a second experiment was carried out as described in Fig. 7a. Twelve mice were used, and each animal received two grafts (a mixture of $500 \mu \mathrm{l}$ of fat together with $50 \mu \mathrm{l}$ of nanofat) on its back. The graft on the left side of the back underwent PBS injection, and the graft on the right side of the back underwent FE injection at days 1, 7, 14, 21 and 28 post-transplantation. The injection was performed at 4 points around the grafted fat and 1 point over the graft $(10 \mu \mathrm{l}$ each point). The grafted fat was harvested and weighed at 12 weeks post-transplantation.

\section{Histological staining}

Fat grafts were fixed in $4 \%$ paraformaldehyde and embedded in paraffin. The samples were then sectioned and stained with haematoxylin-eosin (HE). Fat integrity, vacuoles and fibrosis were evaluated as described by $\mathrm{Hu}$ et al. [22]. For immunohistological staining, paraffinembedded tissue sections were incubated with rabbit antiCD31, anti-Ki67 and anti-perilipin antibodies (Abcam, Cambridge, UK), followed by incubation with a horseradish peroxidase-conjugated secondary antibody (Dako Glostrup, Denmark) or Alexa Fluor 488-conjugated secondary antibodies (Invitrogen, California, USA). CD31-positive blood vessels, Ki67-positive proliferating cells and the percentage area of perilipin-positive adipocytes were calculated. To analyse cell apoptosis, terminal deoxynucleotidyl transferase-mediated d-UTP nick end labelling (TUNEL) staining was performed according to the manufacturer's instructions, and apoptotic cell numbers were calculated. Five random fields were selected for each sample ( $n=3$ /group). All measurements were performed with Image-Pro Plus software (Media Cybernetics; Silver Spring, MD, USA).

\section{Fat tissue culture and measurement of viable adipocytes}

The lipoaspirate was divided into four groups as above: the PBS group, the $\mathrm{FE}^{\mathrm{Low}}$ group, the $\mathrm{FE}^{\mathrm{High}}$ group and the nanofat group. Fat tissue for each group was cultured in an incubator under hypoxic (1\% oxygen) conditions. The fat tissue was then examined by immunostaining with perilipin to detect viable adipocytes at the beginning of tissue culture (day 0 ) and $24 \mathrm{~h}$ later (day 1 ).

\section{Cell culture}

For primary culture of ADSCs, the lipoaspirate was digested with $0.3 \%$ collagenase at $37^{\circ} \mathrm{C}$ for $1 \mathrm{~h}$ and then centrifuged at $1500 \mathrm{rpm}$ for $5 \mathrm{~min}$. The cell pellet was resuspended in Dulbecco's modified Eagle's medium (DMEM) (HyClone) containing 10\% fetal bovine serum (FBS) and 1\% penicillin-streptomycin antibiotic (Gibco, Carlsbad, CA, USA) and then seeded in a cultured dish. Cell passaging was performed until the cells reached 80-90\% confluence. Upon reaching passage 2, FE at different concentrations $(0,1,2$ and $5 \%)$ was added to the cell culture supplements to evaluate the effects of FE on ADSCs. Cell numbers were counted at each passage to evaluate the pro-proliferative effect of FE on ADSCs. Characterization of ADSCs was performed when the cells reached passage 5 .

Human vascular endothelial cells (HUVECs) were purchased from the American Type Culture Collection (ATCC, Rockville, MD, USA) and were maintained in DMEM supplemented with $10 \%$ FBS and $1 \%$ penicillinstreptomycin antibiotic. The culture medium was changed every 2 to 3 days, and the culture was maintained at $37^{\circ} \mathrm{C}$ in a humidified atmosphere of $95 \%$ air and $5 \% \mathrm{CO}_{2}$.

\section{Characterization of ADSCs \\ Trilineage differentiation of ADSCs}

The trilineage differentiation potential of ADSCs was measured as previously described [23]. All chemicals were purchased from Sigma (St. Louis, MO, USA) unless otherwise stated. For adipogenic differentiation, ADSCs were cultured in adipogenic induction medium (penicillin/streptomycin, glutamine, 10\% FBS, insulin, dexamethasone, 3isobutyl-methylxanthine and rosiglitazone) for 21 days, followed by Oil Red O staining. For osteogenic differentiation, ADSCs were cultured for 21 days in an osteogenic 


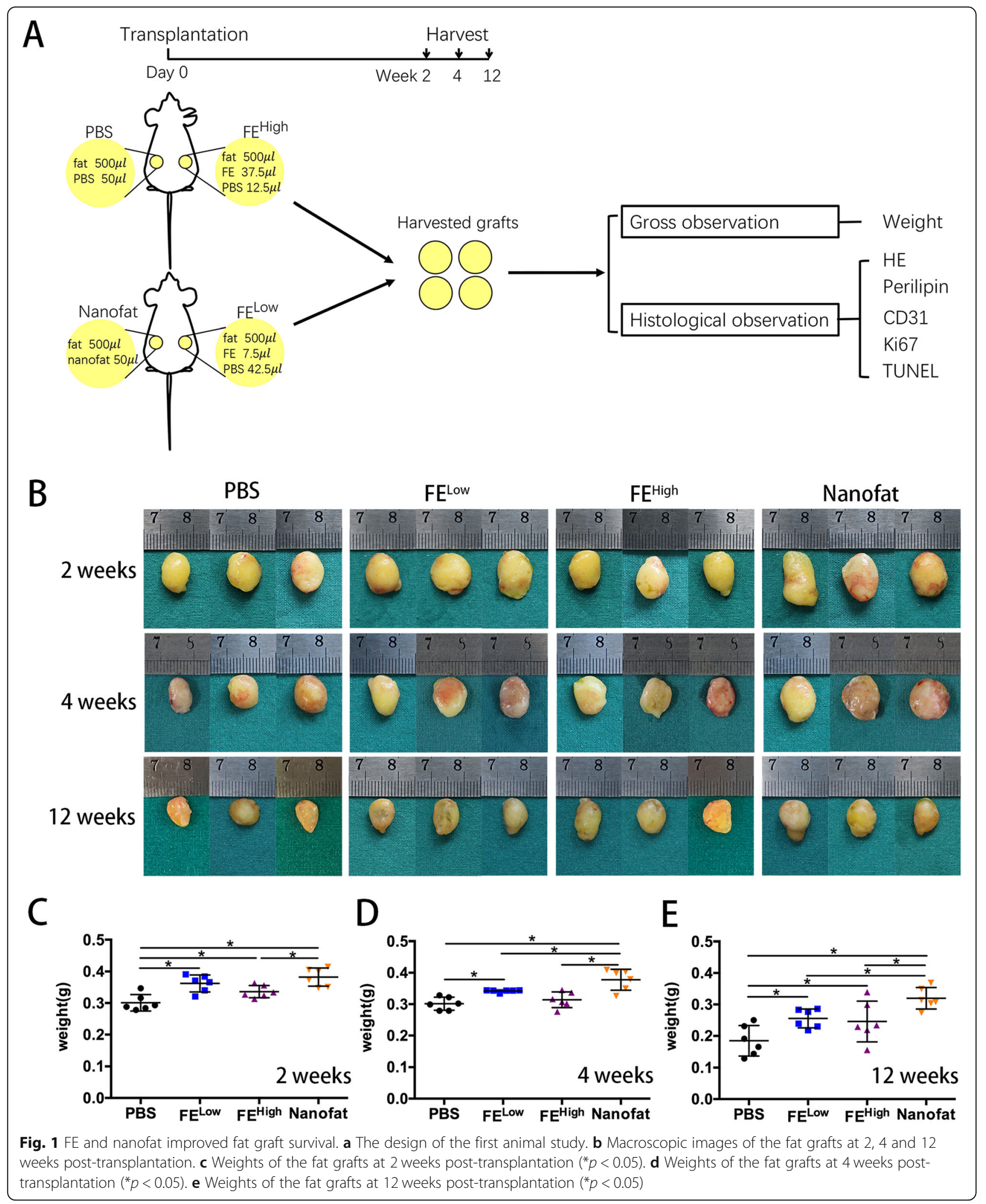

induction medium (penicillin/streptomycin, glutamine, $10 \%$ FBS, dexamethasone, $\beta$-glycerophosphate and ascorbic acid) and then assayed by Alizarin Red staining. For chondrogenic differentiation, $5 \times 10^{5}$ ADSCs were pelleted by centrifugation in a $15-\mathrm{ml}$ culture tube. The pelleted ADSCs were then cultured in chondrogenic induction 
medium using Chondro BulletKit (Lonza Walkersville Inc., Walkersville, MD, USA). After 21 days, the pellet was fixed in $4 \%$ paraformaldehyde, embedded in paraffin, and sectioned and stained with Alcian Blue solution.

\section{Phenotypic profile of ADSCS}

The phenotypic profile of ADSCs was determined by flow cytometry as previously described [24, 25]. Briefly, the cells were collected; stained with phycoerythrin (PE)-conjugated anti-CD11b, anti-CD19, anti-CD34, anti-CD45, anti-HLADR, anti-CD73, anti-CD90 and anti-CD105 antibodies (BD Bioscience, San Jose, CA); and analysed using an Epics Altra flow cytometer (Beckman Coulter, CA, USA).

\section{Cell proliferation assay}

HUVECs were seeded in a 96-well plate at $1 \times 10^{3}$ cells per well and cultured in DMEM medium containing $10 \%$ FBS for $24 \mathrm{~h}$. The cells were then treated for 3 days with different concentrations of FE $(0,1,2$ and 5\%). Untreated cells were used as a control. Cell Counting Kit- 8 (CCK-8; Dojindo Molecular Technologies, Rockville, MD, USA) was used for the cell proliferation assay. The absorbance spectrum at $450 \mathrm{~nm}$ was recorded using a microplate reader (SpectraMAX i3x; Molecular Devices, Sunnyvale, CA, USA).

\section{Cell migration assay}

HUVECs were seeded in 6-well plates and grown to a monolayer. Wounds were created by scratching with a sterile pipette tip, and the medium was replaced with DMEM supplemented with $2 \%$ FBS. FE $(0,1,2,5 \%)$ was added to the medium. Images were captured with a digital camera at 0 and $24 \mathrm{~h}$ after scratching and measured with ImageJ software (NIH, Bethesda, MD, USA). The data are reported as the relative percentage of wounds healed.

\section{Tube formation assay}

A tube formation assay was performed in Matrigel (BD Biosciences). HUVECs were suspended in DMEM supplemented with $2 \%$ FBS. HUVECs $\left(1.5 \times 10^{4}\right)$ were seeded onto Matrigel-coated 96-well plates. The plate was incubated at $37^{\circ} \mathrm{C}$ in $5 \% \mathrm{CO}_{2}$ for $6 \mathrm{~h}$. The cells were then stained with Calcein-AM solution (Yeason, Shanghai, China). Tube formation was photographed under a fluorescence microscope (Carl Zeiss, Oberkochen, Germany). The number of junctions was calculated using ImageJ software (NIH).

\section{Proteinase $\mathrm{K}$ or RNase treatment to investigate the proangiogenic activity of FE}

To investigate whether the protein or ribonucleic acid (RNA) component is essential for the proangiogenic effect of FE, FE was digested with proteinase K (PK) $(20 \mu \mathrm{g} / \mathrm{ml})$ or ribonuclease (RNase) $(200 \mu \mathrm{g} / \mathrm{ml})$ at $37^{\circ} \mathrm{C}$ for $1 \mathrm{~h}$ and then incubated with HUVECs at a concentration of $5 \%$. Cell proliferation assays, migration assays and tube formation assays were performed as described above.

\section{Statistical analysis}

Data are presented as the mean \pm standard deviation. Differences between the groups were analysed using one-way analysis of variance (ANOVA) or non-parametric tests. Statistical analyses were performed using IBM SPSS software (SPSS Statistics V22, IBM Corporation, USA). Values of $p<0.05$ were considered statistically significant.

\section{Results}

FE and nanofat improved fat graft survival

To determine the effects of FE on fat transplantation, human fat tissues were transplanted into nude mice together with PBS, nanofat or FE (Fig. 1a). The fat grafts in each group were harvested at 2, 4 and 12 weeks posttransplantation ( $n=6 /$ time point/group). Representative grafts in each group are shown in Fig. 1b. A decrease in graft size from 2 to 12 weeks was observed in all groups, which was confirmed by measuring the weight of each fat graft (Fig. 1c-e). The weights of the fat grafts in the nanofat group and the FE-treated groups were significantly $(p<0.05)$ higher than those in the PBS group. In addition, the weights of the fat grafts in the nanofat group were significantly $(p<0.05)$ higher than those in the FE-treated groups. No significant difference was observed between the $\mathrm{FE}^{\mathrm{Low}}$ and $\mathrm{FE}^{\mathrm{High}}$ groups.

\section{Histological evaluation of grafts}

At 12 weeks post-transplantation, the grafts were harvested for histological analyses. After HE staining, more small adipocytes were observed in the $\mathrm{FE}^{\text {High }}$ group and the nanofat group (Fig. 2a). Statistical analyses of fat integrity, vacuoles and fibrosis confirmed that higher fat integrity with fewer vacuoles and less fibrosis was observed in the $\mathrm{FE}^{\mathrm{High}}$ group and the nanofat group than in the PBS group and the FE ${ }^{\text {Low }}$ group (Fig. 2b). The viability of adipocytes in each sample was further analysed by perilipin staining. As shown in Fig. 2c, more perilipinpositive viable adipocytes were observed in the $\mathrm{FE}^{\text {High }}$ group and the nanofat group, and significant differences were observed between these two groups and the PBS group (Fig. 2d). These results suggest that FE and nanofat could improve fat graft survival.

\section{Proangiogenic, anti-apoptotic and pro-proliferative effects of FE in vivo}

To investigate the mechanisms of $\mathrm{FE}$ in fat grafting, grafts at 12 weeks post-transplantation were harvested for antiCD31 staining, and grafts at 2 weeks post-transplantation were harvested for TUNEL and anti-Ki67 staining. The 


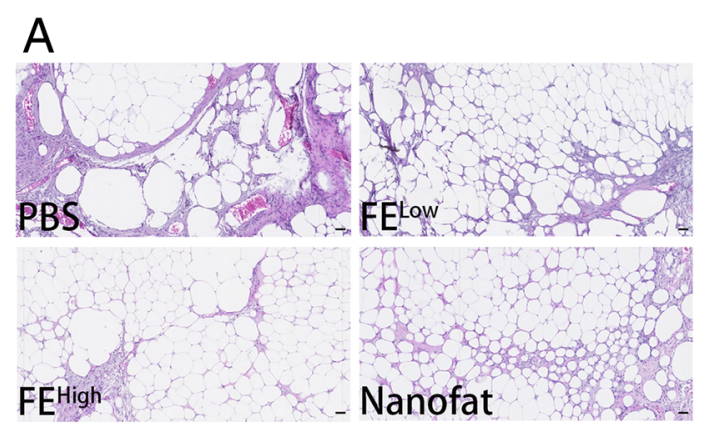

B
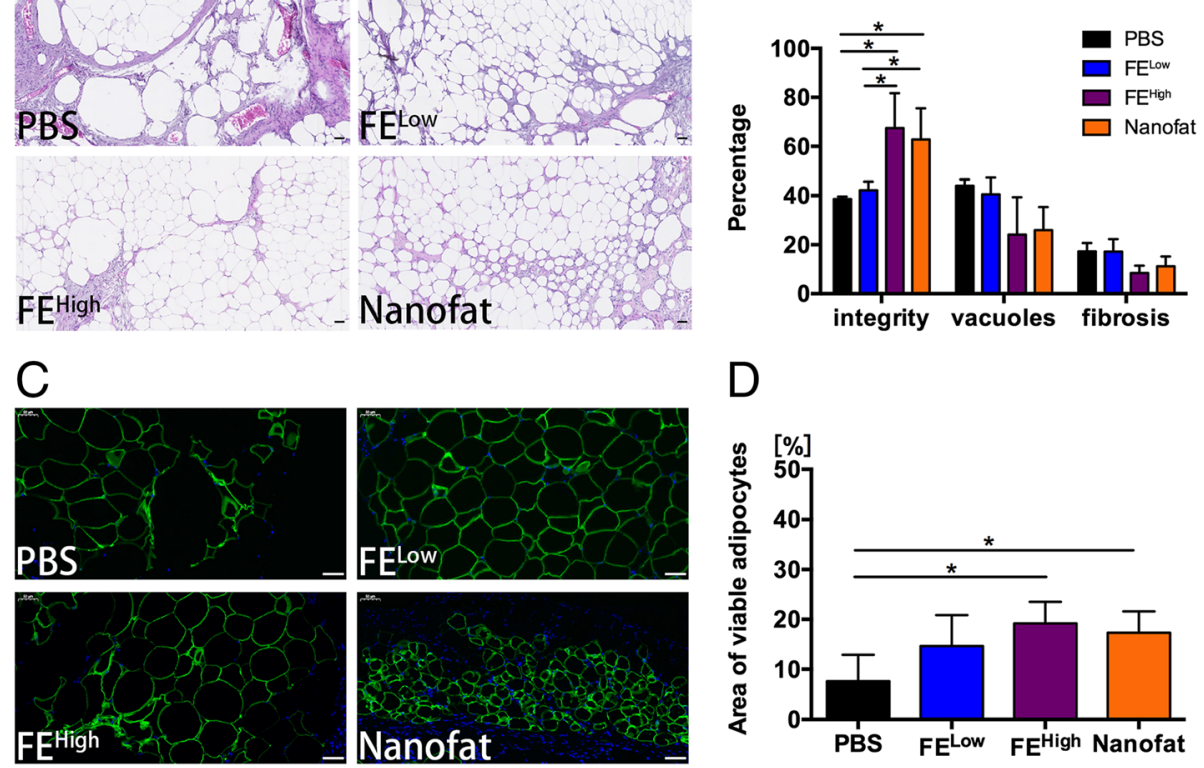

Fig. 2 Histological evaluation of grafts. a HE staining of the harvested fat grafts at 12 weeks post-transplantation. Scale bars $=100 \mu \mathrm{m}$. b Histologic analysis of the grafts at 12 weeks post-transplantation. The percentage areas of integrity, vacuoles and fibrosis were calculated $\left({ }^{*} p<0.05\right)$. c Perilipin staining of the harvested fat grafts at 12 weeks post-transplantation. Scale bars $=50 \mu \mathrm{m}$. $\mathbf{d}$ The percentage area of viable adipocytes in the grafts at 12 weeks post-transplantation was calculated $\left({ }^{*} p<0.05\right)$

number of CD31-positive blood vessels per field in the $\mathrm{FE}^{\text {High }}$ group $(38.29 \pm 4.06)$ and the nanofat group $(40.41 \pm 8.61)$ was significantly higher than that in the PBS group $(22.96 \pm 4.16)$ and the $\mathrm{FE}^{\mathrm{Low}}$ group $(26.32 \pm$ $6.28)(p<0.05)$. No significant difference was observed between the $\mathrm{FE}^{\mathrm{High}}$ group and the nanofat group (Fig. 3a, b), indicating that FE and nanofat could promote neovascularization.

TUNEL staining showed that the average number of apoptotic cells per field in the PBS, the $\mathrm{FE}^{\mathrm{Low}}$, the $\mathrm{FE}^{\mathrm{High}}$ and the nanofat groups were $27.25 \pm 4.53,18.89 \pm 6.08$, $12.52 \pm 4.64$ and $10.96 \pm 5.20$, respectively. There were significantly fewer apoptotic cells in the FE and nanofat groups than in the PBS group (Fig. 3c, d), indicating that FE and nanofat might improve graft survival through their anti-apoptotic activity.

The proliferating cells in the grafts were analysed by antiKi67 staining. As shown in Fig. 3 e and $f$, the numbers of Ki67-positive proliferating cells in the PBS, $\mathrm{FE}^{\mathrm{Low}}, \mathrm{FE}^{\mathrm{High}}$ and nanofat groups were $17.67 \pm 4.69,27.00 \pm 7.23,22.73 \pm$ 6.22 and $29.00 \pm 6.35$ cells per field, respectively. The numbers of proliferating cells in the nanofat and FE groups were significantly higher than those in the PBS group.

\section{Proangiogenic, anti-apoptotic and pro-proliferative effects of FE in vitro}

The proangiogenic, anti-apoptotic and pro-proliferative effects of FE were further confirmed by measuring the effects of FE on cultured vascular endothelial cells, ADSCs and fat tissue in vitro.

To examine the proangiogenic ability, the effects of FE on HUVEC proliferation, migration and tube formation were evaluated. Cell proliferation assays showed that FE promoted HUVEC growth in a dose-dependent manner (Fig. 4a). Cell migration activity analysed by a wound healing assay also showed that FE enhanced the migration of HUVECs in a dose-dependent manner (Fig. 4b, c). An in vitro tube formation assay revealed that more vascular-like structures were formed in the FE-treated groups (Fig. 4d), and the number of junctions was significantly increased in the FE-treated groups (Fig. 4e). FE contains proteins and RNAs. To clarify which component is essential for proangiogenic activity, FE was digested with PK or RNase (a broad-specificity protease or RNase) before incubation with HUVECs. Interestingly, the cell proliferation, migration and tube formation of HUVECs were reduced by PK treatment alone or by PK and RNase co-treatment but not by RNase treatment (Fig. 4f-h), indicating that the proteins in FE are essential for the observed proangiogenic activity.

The anti-apoptotic activity of FE was evaluated by culturing fat tissues under hypoxic conditions in the presence and absence of FE. As shown in Fig. 5, at the beginning of the tissue culture (day 0), no difference in the viable cell area was observed between the control group and the experimental groups. However, 24 h after 

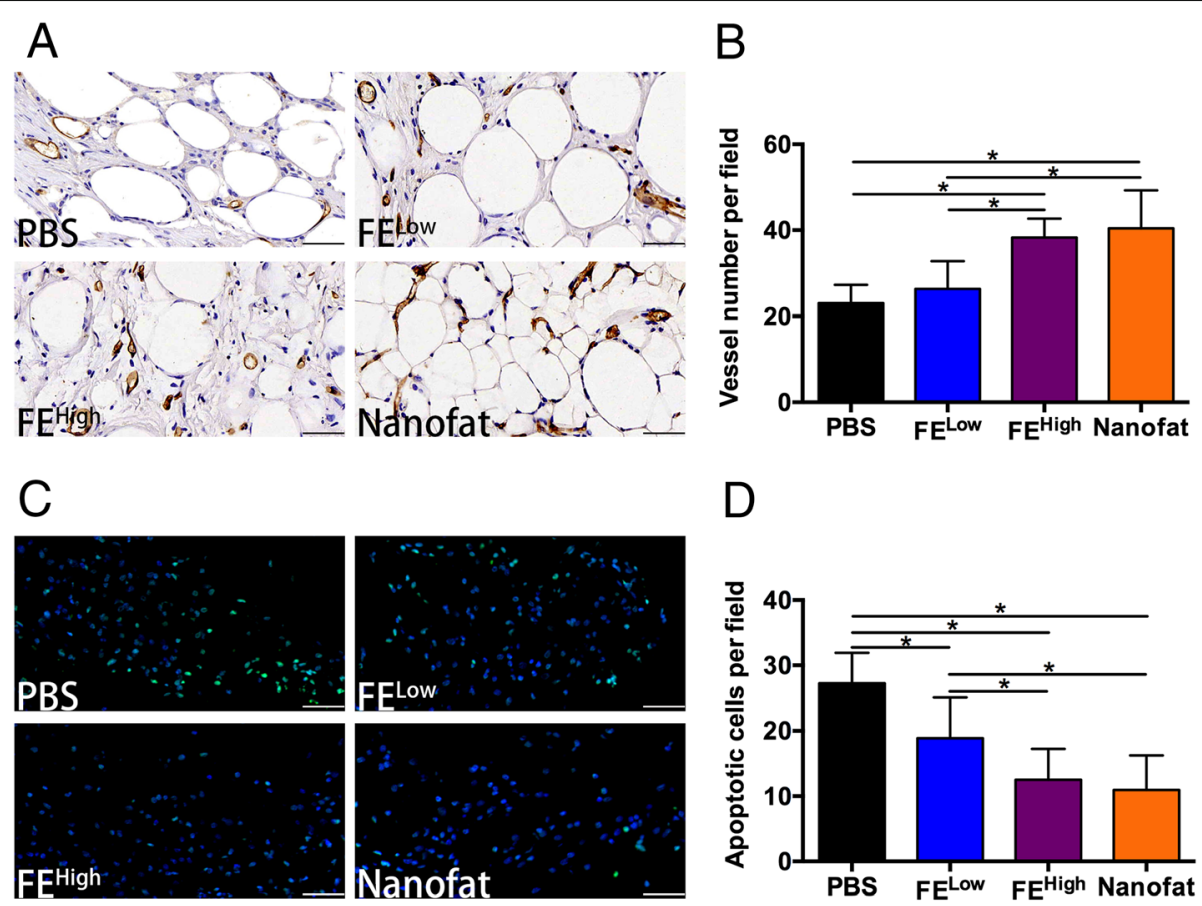

D

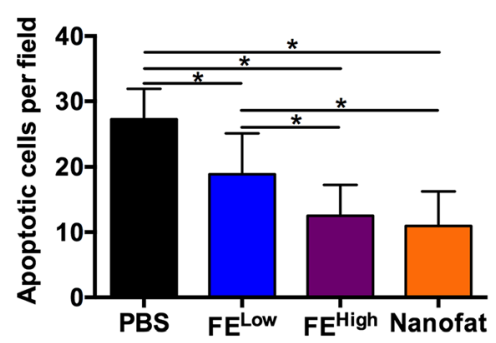

E

$\mathrm{F}$
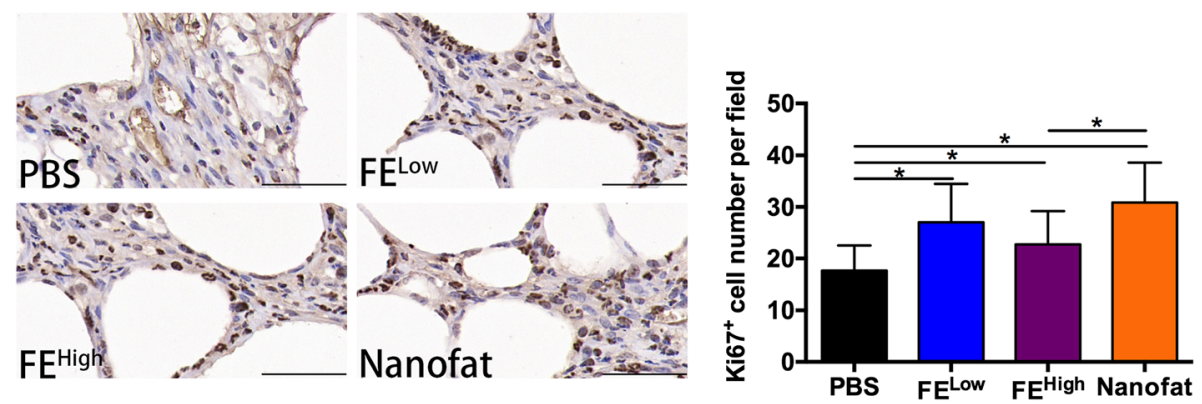

Fig. 3 Proangiogenic, anti-apoptotic and pro-proliferative effects of FE on fat grafts. a Anti-CD31 staining of grafts at 12 weeks posttransplantation. Scale bars $=50 \mu \mathrm{m}$. $\mathbf{b}$ The number of CD31-positive vessels per field in the grafts $\left({ }^{*} p<0.05\right)$. c TUNEL analysis of grafts harvested at 2 weeks post-transplantation. Scale bars $=50 \mu \mathrm{m}$. $\mathbf{d}$ The number of apoptotic cells per field in the grafts $\left({ }^{*} p<0.05\right)$. e Anti-Ki67 staining of grafts at 2 weeks post-transplantation. Scale bars $=50 \mu \mathrm{m}$. $\mathbf{f}$ The number of Ki67-positive cells per field in the grafts $\left({ }^{*} p<0.05\right)$

culture, the adipocyte viability in the $\mathrm{FE}^{\mathrm{Low}}$ and nanofat groups was higher than that in the PBS group, but no statistically significant difference $(p>0.05)$ was observed.

To determine the effect of FE on ADSCs, cells were passaged with different concentrations of FE from passage 2 to passage 5 . Cell counts showed that the cells proliferated more robustly in the presence of FE, with dose-dependent effects (Fig. 6a). Whether the cells that expanded in the presence of FE lost their "stemness", cell surface marker expression and differentiation capacity at passage 5 were analysed. As shown in Fig. $6 \mathrm{~b}$ and c, ADSCs at passage 2 were positive for CD73, CD90 and CD105 and negative for CD11b, CD19, CD34, CD45 and HLA-DR. Increased levels of CD73, CD90 and CD105 expression and decreased levels of CD11b, CD19, CD34,
CD45 and HLA-DR expression were observed in both the FE-treated and non-treated groups. Cell differentiation assays showed that the adipogenic, osteogenic and chondrogenic differentiation capacities of the cells were preserved in the FE-treated groups at passage 5 (Fig. 6d). These results demonstrated that FE could promote ADSC proliferation and maintain their multipotent differentiation capacity.

\section{FE plus nanofat-assisted fat grafting}

To determine whether nanofat and FE work synergistically to promote fat graft survival, macrofat was transplanted with nanofat in nude mice, followed by intra-graft injection of FE at days 1, 7, 14, 21 and 28 post-transplantation (Fig. 7a). The grafts harvested at 12 weeks post-transplantation showed 

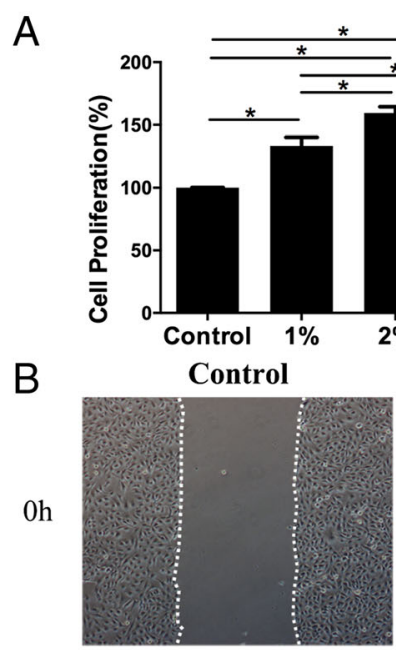

B

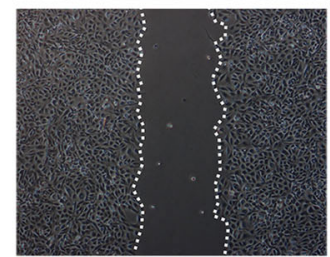

D
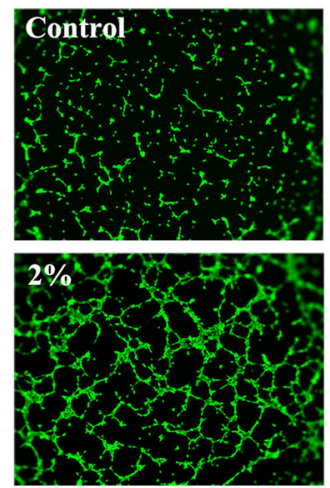

$\mathrm{F}$

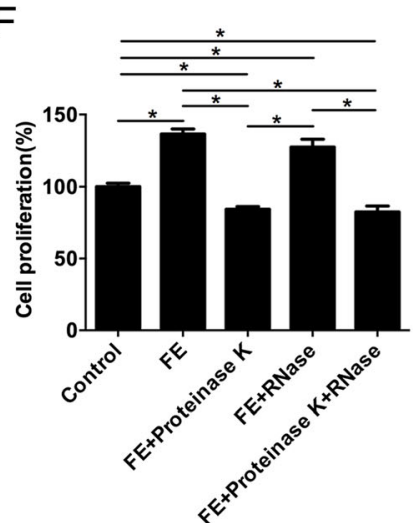

$1 \%$
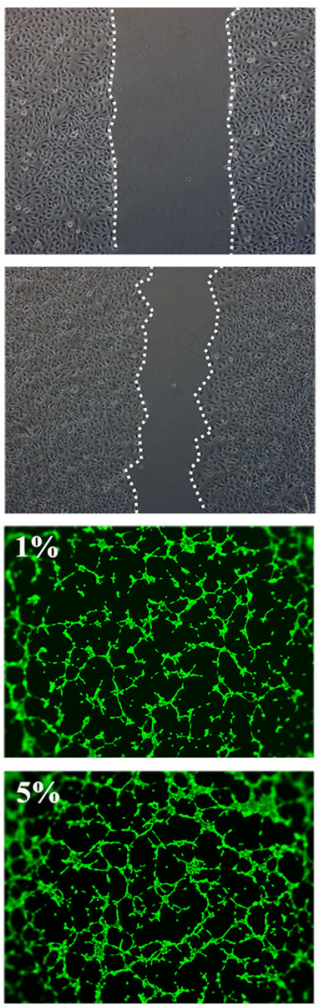

G
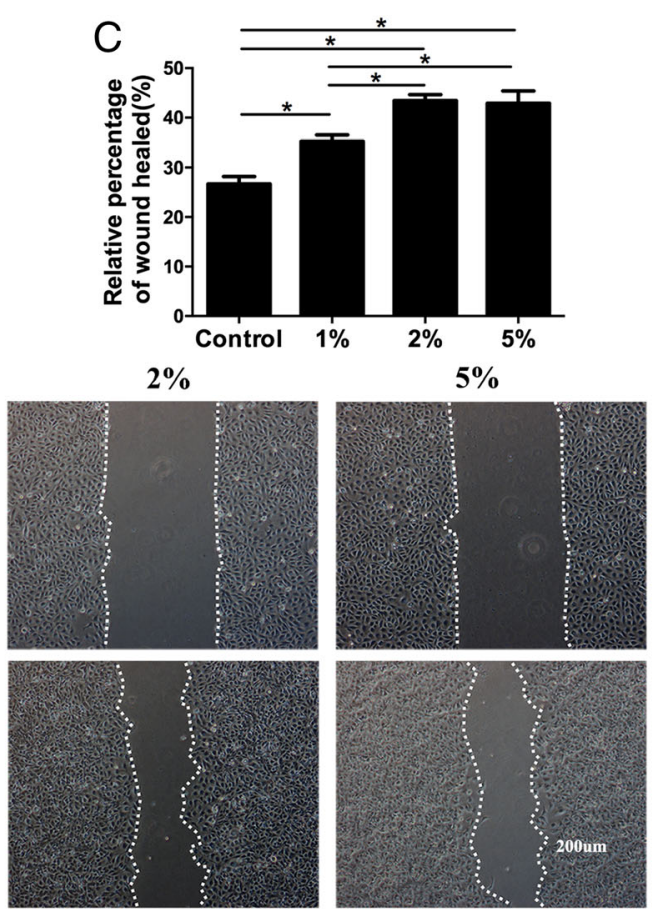

E

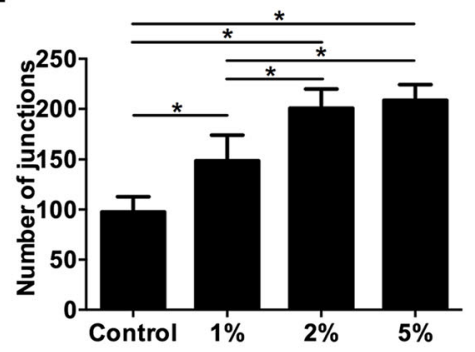

$\mathrm{H}$
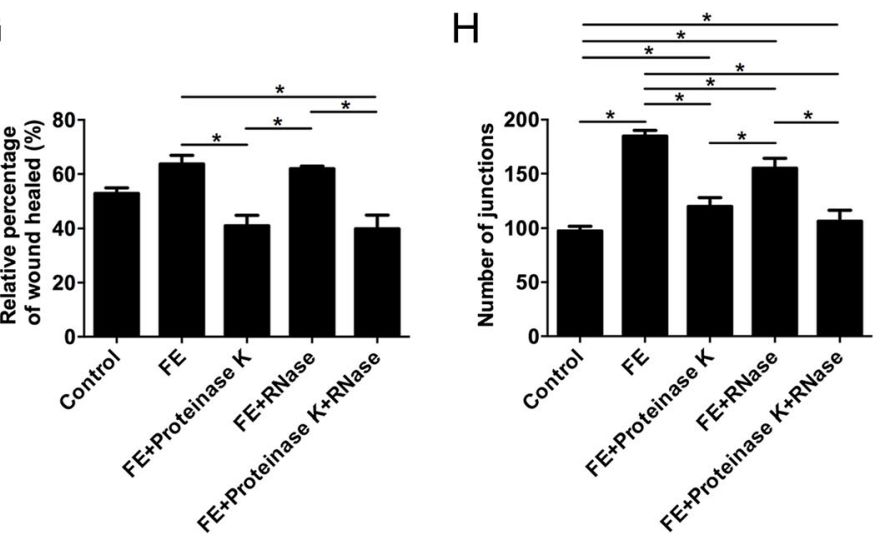

Fig. 4 FE promotes endothelial cell proliferation, migration and tube formation. a Cell proliferation was assessed using a cell counting kit, and the percentage of optical density values relative to the control was calculated $\left({ }^{*} p<0.05\right)$. b HUVEC migration was evaluated using a cell migration assay. $\mathbf{c}$ The relative percentage of wound healing $(24 \mathrm{~h})$ was quantified $\left({ }^{*} p<0.05\right)$. $\mathbf{d}$ Tube formation of HUVECs was performed on solidified Matrigel and stained using Calcein-AM. e The assessment of the number of junctions $/ \mathrm{mm}^{2}$ in each group is shown $\left({ }^{*} p<0.05\right)$. $\mathbf{f}-\mathbf{h}$ FE was digested with PK or RNase before incubation with HUVECs. $\mathbf{f}$ Cell proliferation was assessed using a cell counting kit, and the percentage of optical density values relative to the control was calculated $\left({ }^{*} p<0.05\right)$. $\mathbf{g}$ The relative percentage of wound healing $(24 \mathrm{~h})$ was quantified $\left({ }^{*} p<0.05\right)$. $\mathbf{h}$ The assessment of the number of junctions $/ \mathrm{mm}^{2}$ in each group is shown $\left(^{*} p<0.05\right)$ 
A
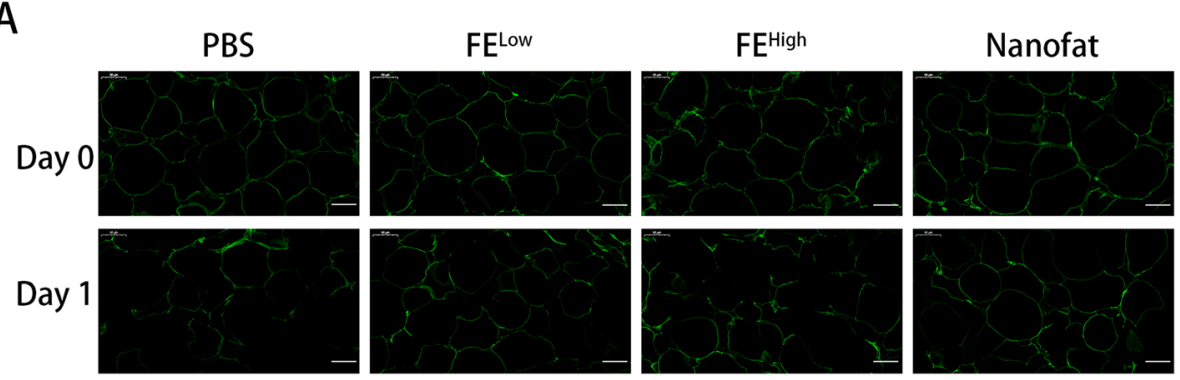

B
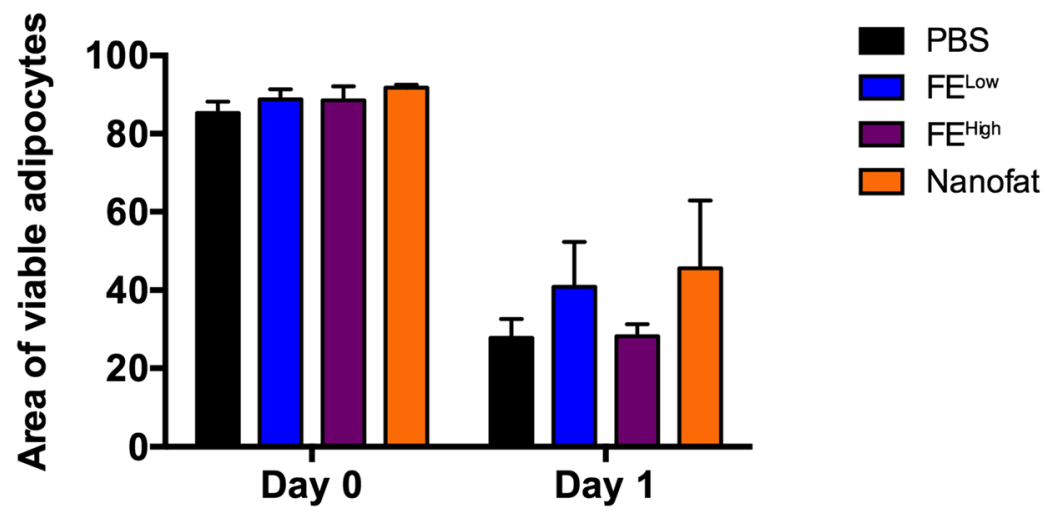

Fig. 5 The anti-apoptotic effects of FE on fat tissues cultured under hypoxic conditions. a Immunofluorescence analysis of adipocyte viability in fat tissue cultured under hypoxic conditions. Scale bars $=50 \mu \mathrm{m}$. $\mathbf{b}$ The percentage area of viable adipocytes of fat tissue at different time points was calculated $\left({ }^{*} p<0.05\right)$

that the size of the grafts in the FE-treated group was larger than that in the PBS-treated group, which was confirmed by measuring the weights of the grafts. The weight of the nanofat+FE group $(0.458 \pm 0.105 \mathrm{~g})$ was significantly higher than that of the nanofat+PBS group $(0.295 \pm 0.052$ g) $(p<0.05)$ (Fig. 7b, c). Histological analysis showed higher fat integrity with less fibrosis in the nanofat+FE group than in the nanofat+PBS group. However, no significant difference was observed between the two groups (Fig. 7d, e).

\section{Discussion}

Our previous research found that nanofat could enhance fat graft survival [20]. In the current study, we demonstrated that the cell-free FE purified from nanofat could also enhance fat graft survival. However, the effects of FE were not as strong as those of nanofat. There are two accepted theories on how fat grafts survive after transplantation, the "graft survival theory" and the "fat regeneration theory". The "graft survival theory", which was established by Peer in the 1950s, states that some transplanted living adipocytes survive and remain alive for a long period of time after grafting $[8,26,27]$. The "regeneration theory" states that adipocytes die early under ischaemic conditions, whereas adipose-derived stem or progenitor cells can survive under ischaemic conditions and are activated and contribute to subsequent adipose tissue regeneration [5]. Nevertheless, vascularization is crucial for fat survival and regeneration. Our previous work showed that nanofat contains a variety of growth factors, including VEGF, TGF- $\beta$, bFGF, HGF, GM-CSF, IGF-1 and PDGF, which could enhance fat graft survival by promoting neovascularization after transplantation [20]. In addition, it has been reported that nanofat also contains ADSCs [16]. In nanofat-assisted fat grafting, live ADSCs in nanofat could survive and possibly participate in fat regeneration. Therefore, co-transplantation of fat with nanofat could achieve better outcomes than cotransplantation with an equivalent amount of cell-free FE (Fig. 1). In the current study, a decrease in graft size from 2 to 12 weeks was observed in all groups, which was consistent with other studies [28, 29]. The absorption period of dead adipocytes by macrophage phagocytosis within 3 months after transplantation accounts for the atrophy of the grafted fat [26].

Cytokines and growth factors, including brain-derived neurotrophic factor (BDNF), glial cell-derived neurotrophic factor (GDNF), TGF- $\beta$, HGF, bFGF, VEGF, PDGF, epidermal growth factor (EGF), neurotrophin-3 (NT-3) and G-CSF, have been detected in FE, and the proangiogenic effect of $\mathrm{FE}$ has been proven in ischaemic animal model [21]. In the current study, we also found 
A

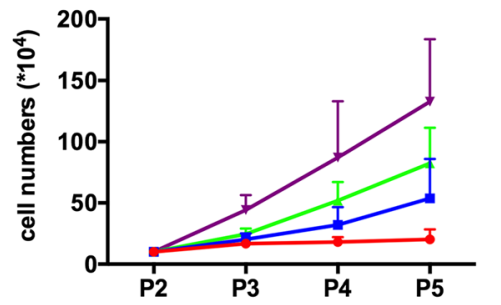

C
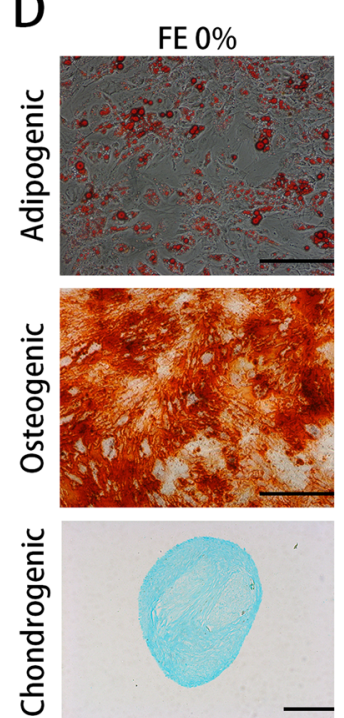

B

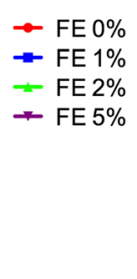

P5
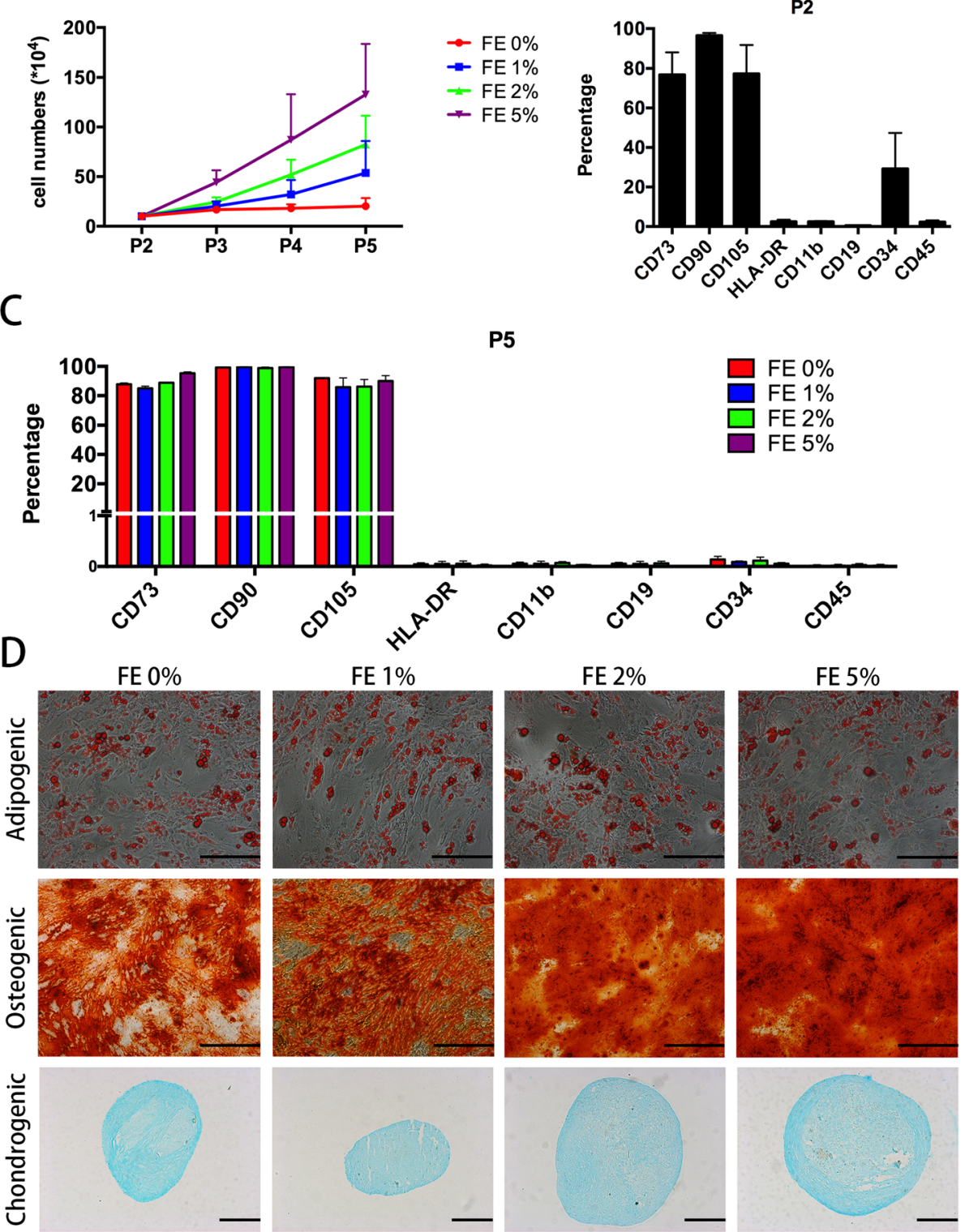

Fig. 6 FE promotes ADSC proliferation and maintains their multipotent differentiation capacity. a ADSCs were treated with FE at the indicated concentrations. Cell proliferation was assessed by counting the cell numbers at each passage. $\mathbf{b}$ The cell surface marker expression of ADSCs at passage 2 was analysed. c The cell surface marker expression of ADSCs at passage 5 was analysed. $\mathbf{d}$ The differentiation capacity of human ADSCs into the adipogenic, osteogenic and chondrogenic lineages was analysed. Differentiation was detected with Oil Red O, von Kossa and Alcian Blue staining. Scale bars $=100 \mu \mathrm{m}$

more CD31-positive blood vessels in the FE groups than in the control group (Fig. 3a, b), indicating that FE enhances fat graft survival partially through the stimulation of new vessel formation. FE contains a variety of proteins and RNase [21]. Interestingly, when FE was predigested with PK or RNase, its proangiogenic activity was significantly diminished by PK treatment but not RNase treatment (Fig. $4 \mathrm{f}-\mathrm{h}$ ), indicating that the protein fraction of FE is essential for its proangiogenic activity. Based on the proteomic analysis in our previous study
[21], we speculate that such effects are likely attributed to the presence of well-known proangiogenic factors in FE, such as VEGF, PDGF, bFGF and HGF. We also believe that no significant differences could be observed by simply blocking one or two factors. It is difficult to measure which of these factors plays a key role in FE.

It is well known that cell apoptosis and necrosis tend to occur under ischaemic conditions. Eto et al. demonstrated that adipocytes had poor tolerance to ischaemic stress compared to endothelial cells and ADSCs and 

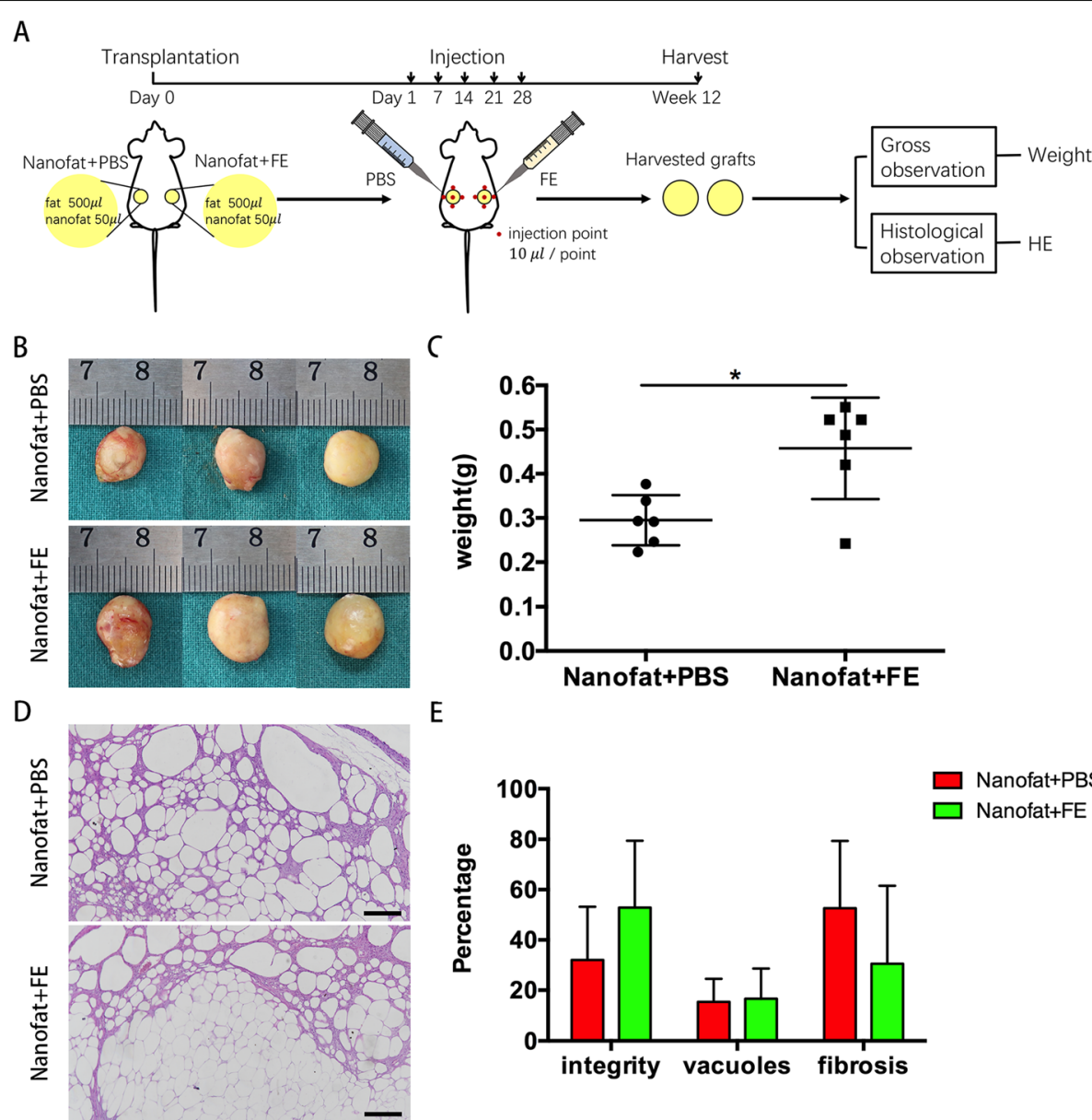

E

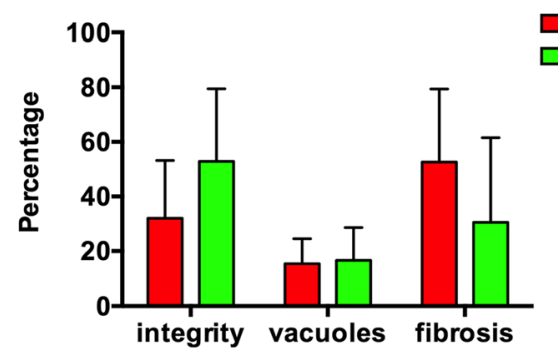

Fig. 7 Nanofat and FE work synergistically to promote fat graft survival. a The design of the second animal study. $\mathbf{b}$ Macroscopic images of the fat grafts at 12 weeks post-transplantation. $\mathbf{c}$ Weights of the fat grafts at 12 weeks post-transplantation $\left({ }^{*} p<0.05\right)$. $\mathbf{d}$ HE staining of the harvested fat grafts at 12 weeks post-transplantation. Scale bars $=100 \mu \mathrm{m}$. e Histologic analysis to evaluate the grafts at 12 weeks post-transplantation. The percentage areas of integrity, vacuoles and fibrosis were calculated $\left.{ }^{*} p<0.05\right)$

underwent apoptosis and necrosis as early as $12 \mathrm{~h}$ under ischaemia-mimicking conditions [5]. In the current study, fewer TUNEL-positive apoptotic cells were observed in the grafts co-transplanted with FE or nanofat (Fig. 3c, d). Furthermore, in vitro culture of fat tissue under hypoxic conditions showed that more dead cells were observed after $24 \mathrm{~h}$ of culture in the control group, while fewer dead cells were observed in the FE- or nanofat-treated groups (Fig. 5), indicating that FE and nanofat exert anti-apoptotic effects on adipocytes. The presence of VEGF, HGF and IGF-1 may account for these results. Synergistic effects of combined gene delivery on enhanced VEGF secretion were reported to decrease cardiomyocyte apoptosis under hypoxic conditions [30]. Jang et al. reported that HGF-treated hepatocytes showed better cell viability, with increased expression of Mcl-1, an anti-apoptotic protein, and decreased expression of proapoptotic proteins (Bad, Bik and Bid) in HGF-treated hepatocytes [31]. It was reported that lentiviral-mediated overexpression of the IGF-1 gene in ADSCs could prolong the anti-apoptotic effects by activating the PI3K/Akt pathway [32]. The anti-apoptotic mechanism of $\mathrm{FE}$ is not clear. We found that FE could prevent dermal fibroblast death induced by ultraviolet irradiation by reducing intracellular reactive oxygen species accumulation (unpublished data). The antioxidant pathway may play a role in the antiapoptotic effects of FE on adipocytes.

According to the "fat regeneration theory", ADSCs play a significant role in adipose tissue regeneration because they can survive under ischaemic conditions and produce new adipocytes to replace dead adipocytes [5]. In the current study, more Ki67-positive proliferating cells were observed in the grafts co-transplanted with $\mathrm{FE}$ and nanofat (Fig. 3e, f). In vitro culture of ADSCs showed that FE could promote ADSC proliferation in a dosedependent manner (Fig. 6a). More importantly, cells that expanded in the presence of FE maintained their "stemness", which was demonstrated by the consistent expression 


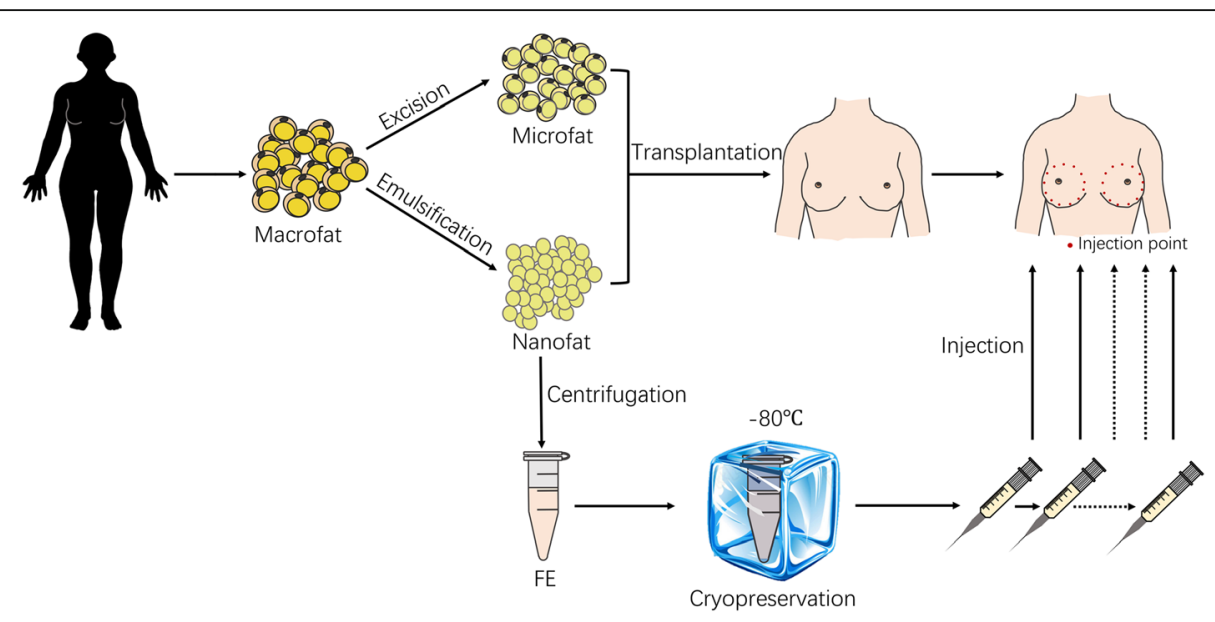

Fig. 8 A new FE plus nanofat-assisted fat grafting strategy for future clinical application

of cell surface markers, and retained their multipotent differentiation capacity at passage 5 (Fig. 6b, c). These results suggested that co-transplanted FE might stimulate the proliferation of surviving ADSCs in the grafts that would produce more adipogenic progenitors during the subsequent fat regeneration process. Cai et al. proposed that haematopoietic stem cells in the host could be mobilized and recruited to the site of transplanted fat to facilitate better survival [33]. Whether FE can recruit adipogenic progenitors to the graft and contribute to fat regeneration should be investigated in the future. In the current study, we injected a given volume of FE for each experiment. It is better to normalize the injection by measuring the amount of growth factors in each donor, because the composition of FE maybe different from individuals with different age, gender and body mass index. Although our previous study did not found a big difference between the samples from 6 donors using ELISA analysis [21], it is worth to be analysed with more samples in the future.

Although nanofat showed a better improvement of fat survival than FE, it has several limitations because of its cellular component, including the difficulties of longterm storage for multiple administrations. In contrast, without cellular or oil fractions, FE can theoretically avoid cell-related concerns and undergo long-term storage more successfully. Taking advantage of nanofat and FE, we proposed a new strategy for fat grafting. Macrofat was first co-transplanted with nanofat, followed by 5 intra-graft injections of FE weekly post-transplantation. Better fat graft retention was observed in the nanofat+FE group than in the nanofat+PBS group (Fig. 7). These results prove that FE and nanofat synergistically improved fat graft survival. Therefore, for future clinical applications, if enough fat tissue could be aspirated from the donor site, part of the fat could be prepared into microfat for transplantation into the defects, part of the fat could be emulsified into nanofat and co-transplanted immediately as an assisting component, and the rest of the fat could be processed to obtain FE for subsequent intra-graft injections (Fig. 8). The microfat/nanofat/FE ratio in the graft should be optimized in future studies.

\section{Conclusions}

The current study demonstrated that cell-free FE could improve fat graft survival via proangiogenic, anti-apoptotic and pro-proliferative effects on ADSCs. FE plus nanofatassisted fat grafting is a new strategy that could potentially be used in clinical applications.

\section{Abbreviations}

ADSCs: Adipose-derived stem cells; BDNF: Brain-derived neurotrophic factor; bFGF: Basic fibroblast growth factor; DMEM: Dulbecco's modified Eagle medium; EGF: Epidermal growth factor; FBS: Fetal bovine serum; FE: Fat extract; GM-CSF: Granulocyte-macrophage colony-stimulating factor; HGF: Hepatocyte growth factor; HUVECs: Human vascular endothelial cells; IGF-1: Insulin-like growth factor 1; PBS: Phosphate-buffered saline; PDGF: Platelet-derived growth factor; RNA: Ribonucleic acid;

RNase: Ribonuclease; SVF: Stromal vascular fraction; TGF- $\beta$ : Transforming growth factor beta; VEGF: Vascular endothelial growth factor

\section{Acknowledgements}

The authors would like to thank all of the members of the Shanghai Key Laboratory of Tissue Engineering for the discussions and help with this study.

\section{Authors' contributions}

WL, WZ and LZ contributed to the conception, study design and data interpretation. $\mathrm{HZ}, \mathrm{ZY}$ and $\mathrm{MD}$ conducted the study, experimentation, manuscript writing and editing. YC contributed to the data collection and analysis. XW and YX contributed to the sample collection and processing. All authors read and approved the final manuscript.

\section{Funding}

This work was supported by the National Natural Science Foundation of China (81771993), the National Key Research and Development Program of China (2016YFC1101400), the Shanghai Collaborative Innovation Program on Regenerative Medicine and Stem Cell Research (2019CXJQ01) and the Natural Science Foundation of Shanghai (16ZR1419800). The funder had no role in the data collection, data management, data analysis, decision to publish or preparation of the manuscript. 


\section{Availability of data and materials}

The datasets generated during and/or analysed during the current study are available from the corresponding author on reasonable request.

\section{Ethics approval and consent to participate}

The study was approved by the Ethics Committee of Shanghai Jiaotong University School of Medicine, Shanghai, China.

\section{Consent for publication}

Not applicable.

\section{Competing interests}

The authors declare that they have no competing interests.

Received: 23 March 2019 Revised: 14 May 2019

Accepted: 30 May 2019 Published online: 13 June 2019

\section{References}

1. Coleman SR. Structural fat grafting: more than a permanent filler. Plast Reconstr Surg. 2006;118(3 Suppl):108s-20s.

2. Zhu M, Cohen SR, Hicok KC, Shanahan RK, Strem BM, Yu JC, et al. Comparison of three different fat graft preparation methods: gravity separation, centrifugation, and simultaneous washing with filtration in a closed system. Plast Reconstr Surg. 2013;131(4):873-80.

3. Peer LA, Walker JC Jr. The behavior of autogenous human tissue grafts: a comparative study. Plast Reconstr Surg (1946). 1951;7(1):6-23 contd.

4. Coleman SR. Structural fat grafts: the ideal filler? Clin Plast Surg. 2001;28(1): $111-9$.

5. Eto $H$, Kato H, Suga H, Aoi N, Doi K, Kuno S, et al. The fate of adipocytes after nonvascularized fat grafting: evidence of early death and replacement of adipocytes. Plast Reconstr Surg. 2012;129(5):1081-92.

6. Suszynski TM, Sieber DA, Cunningham BL, Van Beek AL. Implications of oxygenation in fat grafting. Plast Reconstr Surg. 2014;133(5):731e-3e.

7. Lancerotto L, Chin MS, Freniere B, Lujan-Hernandez JR, Li Q, Valderrama Vasquez $A$, et al. Mechanisms of action of external volume expansion devices. Plast Reconstr Surg. 2013;132(3):569-78.

8. Carpaneda CA, Ribeiro MT. Percentage of graft viability versus injected volume in adipose autotransplants. Aesthet Plast Surg. 1994;18(1):17-9.

9. Niechajev I, Sevcuk O. Long-term results of fat transplantation: clinical and histologic studies. Plast Reconstr Surg. 1994;94(3):496-506.

10. Gir P, Brown SA, Oni G, Kashefi N, Mojallal A, Rohrich RJ. Fat grafting: evidence-based review on autologous fat harvesting, processing, reinjection, and storage. Plast Reconstr Surg. 2012;130(1):249-58.

11. Matsumoto D, Sato K, Gonda K, Takaki Y, Shigeura T, Sato T, et al. Cellassisted lipotransfer: supportive use of human adipose-derived cells for soft tissue augmentation with lipoinjection. Tissue Eng. 2006;12(12):3375-82.

12. Han YD, Bai Y, Yan XL, Ren J, Zeng Q, Li XD, et al. Co-transplantation of exosomes derived from hypoxia-preconditioned adipose mesenchymal stem cells promotes neovascularization and graft survival in fat grafting. Biochem Biophys Res Commun. 2018;497(1):305-12.

13. Cervelli V, Scioli MG, Gentile P, Doldo E, Bonanno E, Spagnoli LG, et al. Platelet-rich plasma greatly potentiates insulin-induced adipogenic differentiation of human adipose-derived stem cells through a serine/ threonine kinase Akt-dependent mechanism and promotes clinical fat graft maintenance. Stem Cells Transl Med. 2012;1(3):206-20.

14. Garza RM, Rennert RC, Paik KJ, Atashroo D, Chung MT, Duscher D, et al. Studies in fat grafting: part IV. Adipose-derived stromal cell gene expression in cell-assisted lipotransfer. Plast Reconstr Surg. 2015;135(4):1045-55.

15. Hong KY, Yim S, Kim HJ, Jin US, Lim S, Eo S, et al. The fate of the adiposederived stromal cells during angiogenesis and adipogenesis after cellassisted lipotransfer. Plast Reconstr Surg. 2018;141(2):365-75.

16. Tonnard P, Verpaele A, Peeters $G$, Hamdi M, Cornelissen M, Declerca H. Nanofat grafting: basic research and clinical applications. Plast Reconstr Surg. 2013;132(4):1017-26.

17. Gu Z, Li Y, Li H. Use of condensed nanofat combined with fat grafts to treat atrophic scars. JAMA Facial Plast Surg. 2018;20(2):128-35.

18. Kemaloglu CA. Nanofat grafting under a split-thickness skin graft for problematic wound management. Springerplus. 2016;5:138.

19. Wei H, Gu SX, Liang YD, Liang ZJ, Chen H, Zhu MG, et al. Nanofat-derived stem cells with platelet-rich fibrin improve facial contour remodeling and skin rejuvenation after autologous structural fat transplantation. Oncotarget. 2017;8(40):68542-56.

20. Yu Q, Cai Y, Huang H, Wang Z, Xu P, Wang X, et al. Co-transplantation of nanofat enhances neovascularization and fat graft survival in nude mice. Aesthet Surg J. 2018;38(6):667-75.

21. Yu Z, Cai Y, Deng M, Li D, Wang X, Zheng $H$, et al. Fat extract promotes angiogenesis in a murine model of limb ischemia: a novel cell-free therapeutic strategy. Stem Cell Res Ther. 2018;9(1):294.

22. Hu Y, Jiang Y, Wang M, Tian W, Wang $\mathrm{H}$. Concentrated growth factor enhanced fat graft survival: a comparative study. Dermatologic Surg. 2018; 44(7):976-84.

23. Chieregato K, Castegnaro S, Madeo D, Astori G, Pegoraro M, Rodeghiero F. Epidermal growth factor, basic fibroblast growth factor and platelet-derived growth factor-bb can substitute for fetal bovine serum and compete with human platelet-rich plasma in the ex vivo expansion of mesenchymal stromal cells derived from adipose tissue. Cytotherapy. 2011;13(8):933-43.

24. Doi K, Ogata F, Eto H, Kato H, Kuno S, Kinoshita K, et al. Differential contributions of graft-derived and host-derived cells in tissue regeneration/ remodeling after fat grafting. Plast Reconstr Surg. 2015;135(6):1607-17.

25. Rasmussen BS, Sorensen CL, Vester-Glowinski PV, Herly M, Kurbegovic S, Orholt $\mathrm{M}$, et al. A novel porcine model for future studies of cell-enriched fat grafting. Plast Reconstr Surg Global Open. 2018;6(4):e1735.

26. Pu LL. Mechanisms of fat graft survival. Ann Plast Surg. 2016;77(Suppl 1): S84-6.

27. Zhao J, Yi C, Li L, Zheng Y, Wu K, Liang L, et al. Observations on the survival and neovascularization of fat grafts interchanged between C57BL/6-gfp and C57BL/6 mice. Plast Reconstr Surg. 2012;130(3):398e-406e.

28. Zhu M, Dong Z, Gao J, Liao Y, Xue J, Yuan Y, et al. Adipocyte regeneration after free fat transplantation: promotion by stromal vascular fraction cells. Cell Transplant. 2015;24(1):49-62.

29. Kokai LE, Jones TL, Silowash R, Theisen B, DiBernardo G, Lu A, et al. Optimization and standardization of the immunodeficient mouse model for assessing fat grafting outcomes. Plast Reconstr Surg. 2017;140(6):1185-94.

30. Won YW, Lee M, Kim HA, Nam K, Bull DA, Kim SW. Synergistically combined gene delivery for enhanced VEGF secretion and antiapoptosis. Mol Pharm. 2013;10(10):3676-83.

31. Jang YH, You DH, Nam MJ. Protective effects of HGF gene-expressing human mesenchymal stem cells in acetaminophen-treated hepatocytes. Growth Factors (Chur, Switzerland). 2015;33(5-6):319-25.

32. Chen T, Huang D, Chen G, Yang T, Yi J, Tian M. Efficient and sustained IGF-1 expression in the adipose tissue-derived stem cells mediated via a lentiviral vector. J Mol Histol. 2015;46(1):1-11.

33. Cai J, Feng J, Liu K, Zhou S, Lu F. Early macrophage infiltration improves fat graft survival by inducing angiogenesis and hematopoietic stem cell recruitment. Plast Reconstr Surg. 2018;141(2):376-86.

\section{Publisher's Note}

Springer Nature remains neutral with regard to jurisdictional claims in published maps and institutional affiliations.

Ready to submit your research? Choose BMC and benefit from:

- fast, convenient online submission

- thorough peer review by experienced researchers in your field

- rapid publication on acceptance

- support for research data, including large and complex data types

- gold Open Access which fosters wider collaboration and increased citations

- maximum visibility for your research: over $100 \mathrm{M}$ website views per year

At BMC, research is always in progress.

Learn more biomedcentral.com/submissions 